\title{
Acquired C1 Inhibitor (C1-INH) Deficiency Type II Replacement Therapy with C1-INH and Analysis of Patients' C1-INH and Anti-C1-INH Autoantibodies
}

Jochem Alsenz, ${ }^{\star \ddagger}$ John D. Lambris, ${ }^{\ddagger}$ Konrad Bork,

${ }^{*}$ Institute of Medical Microbiology, Johannes-Gutenberg University, D-6500 Mainz, Federal Republic of Germany; ${ }^{\ddagger}$ Basel Institute for Immunology, CH-4005 Basel, Switzerland; and '\$ Department of Dermatology, Johannes-Gutenberg University, D-6500 Mainz, Federal Republic of Germany

\begin{abstract}
The response of two patients with autoantibody-mediated C1inhibitor (C1-INH) deficiency to replacement therapy with C1-INH was studied over a period of $3 \mathrm{~d}$. In patient 1 an acute attack of angioedema was successfully managed by infusion of $1,000 \mathrm{U}$ of C1-INH concentrate. C1-INH function returned to normal levels within $30 \mathrm{~min}$, while $\mathrm{CH50}$ and $\mathrm{C} 4$ peaked after 6-7 $\mathrm{h}$ and $\mathrm{Cl}$ hemolytic activity reached $50-60 \%$ of normal after $3 \mathrm{~d}$. Immediately after the injection an increase in C1INH-anti-C1-INH complexes was observed. Based on $\mathbf{N H}_{2}-$ terminal sequence analysis of the patients' $M_{\mathrm{r}} 96,000 \mathrm{C1}-\mathrm{INH}$, it is concluded that this fragment is generated after cleavage of C1-INH in its active site by one of its target proteases without generating a covalent $\mathrm{C1}$-INH-enzyme complex. In a second patient with a four to five times higher anti-C1-INH antibody titer, the infusion of $500 \mathrm{ml}$ of plasma or of $2,000 \mathrm{U}$ of $\mathrm{C1}-\mathrm{INH}$ concentrate influenced neither the severity of the patient's angioedema nor the tested parameters, except for an increase in the amount of C1-INH-anti-C1-INH complexes. Analysis of patients' anti-C1-INH antibodies revealed that the antibodies recognize different epitopes within the $\mathrm{C} 1-\mathrm{INH}$. This suggests that patients with acquired angioedema type $\mathrm{H}$ are a heterogenous group with respect to the C1-INH autoantibodies.
\end{abstract}

\section{Introduction}

The complement component $\mathrm{C} 1$-inhibitor $(\mathrm{C} 1 \text {-INH })^{1}$ controls the spontaneous autoactivation of the first complement component $(\mathrm{Cl})$ as well as activated $\mathrm{Cl}$ (1). In humans a functional deficiency of $\mathrm{Cl}-\mathrm{INH}$ is associated with complement activation and recurrent angioedema $(2,3)$. The syndrome of hereditary angioedema (HAE) is the most common form of this disease and is related either to a decreased synthesis of apparently normal C1-INH protein (HAE type I) (4-6) or to the presence of a dysfunctional protein (HAE type II) (7-9). A deficiency of $\mathrm{Cl}-\mathrm{INH}$ may also be acquired and is usually

This work was presented in part at the XIIth International Complement Workshop, Chamonix, France.

Address reprint requests to Dr. Jochem Alsenz, Basel Institute for Immunology, Granzacherstrasse 487, CH-4005 Basel 5, Switzerland.

Received for publication $19 \mathrm{July} 1988$ and in revised form $23 \mathrm{No}$ vember 1988.

1. Abbreviations used in this paper: $\mathrm{AAE}$, acquired angioedema; $\mathrm{C1}$ INH, C1-inhibitor; HAE, hereditary angioedema.

J. Clin. Invest.

(c) The American Society for Clinical Investigation, Inc. $0021-9738 / 89 / 06 / 1794 / 06 \$ \$ 2.00$

Volume 83, June 1989, 1794-1799 associated with a lymphoproliferative disease or other malignancies (acquired C1-INH deficiency type I, acquired angioedema [AAE] type I) (10-13). Both HAE and AAE are characterized by low levels or absence of $\mathrm{C} 2, \mathrm{C} 4$, and functionally active $\mathrm{Cl}-\mathrm{INH}(6,10,14)$. In contrast to the hereditary form, patients with AAE show a marked decrease of $\mathrm{Cl}$ levels, a normal or slightly increased C1-INH synthesis, and an onset of symptoms in middle age $(10,13)$. The deficiency of C1-INH in these patients has been suggested to result from an accelerated catabolism of C1-INH due to increased activation of $\mathrm{C1}$ (13).

Recently, we have reported a new type of acquired C1-INH deficiency caused by autoantibodies against C1-INH (AAE type II) (15). The serum of these patients contained considerable amounts of an IgG1 anti-C1-INH antibodies that interfered with $\mathrm{C} 1-\mathrm{INH}$ function. In addition, the $\mathrm{Cl}$-INH found in these patients had a molecular mass of only 96,000 D (normal $\mathrm{Cl}-\mathrm{INH}, 105,000 \mathrm{D})$ and was functionally inactive. It was present in plasma at $60-70 \%$ of the normal protein level of C1-INH. This molecule presumably resulted from the degradation of $M_{\mathrm{r}} 105,000 \mathrm{Cl}$-INH by activated C1s in plasma. In contrast to AAE type I, no other associated diseases were diagnosed in this new type of AAE. Presently, five patients with AAE type II have been reported, three with IgG and two with IgA autoantibodies to C1-INH (15-18).

Long-term prophylactic drug treatment with antifibrinolytic agents, danazol, or other androgens is often successfully used to prevent the potentially lethal manifestations of angioedema in patients with HAE or AAE type $I(6,14,19,20)$. Acute, life-threatening attacks in these types of angioedema have been successfully managed by replacement therapy with C1-INH concentrate (21-23). However, drug treatment in patients with AAE type II failed to correct the complement abnormalities $(15,24)$. In addition, one patient was found to be resistant to replacement therapy with purified $\mathrm{C} 1-\mathrm{INH}$ or fresh frozen plasma (15).

In this study we investigated the efficacy of C1-INH replacement therapy in two patients with AAE type II and studied several biochemical parameters in patients' plasma after administration of $\mathrm{Cl}$-INH. Some of the factors responsible for the therapy resistance of these patients were determined. In addition, the patients' C1-INH molecules and anti-C1-INH antibodies were characterized by sequence analysis and binding studies, respectively.

\section{Methods}

Protein purification. C1-INH and activated $\mathrm{Cls}$ were purified as previously described $(15,25)$. In brief, $M_{\mathrm{r}} 105,000 \mathrm{C} 1-\mathrm{INH}$ or patients' C1-INH was affinity purified from plasma on a MAb 13E1 Sepharose column. This antibody recognized the $M_{\mathrm{r}} 96,000 \mathrm{C} 1$-INH fragment. After washing the column, bound C1-INH was eluted with $3 \mathrm{M}$ 
$\mathrm{NaCl} / 50 \%$ ethyleneglycol/PBS and dialyzed against PBS. C1-INH was labeled with ${ }^{125} \mathrm{I}$ as described (15).

C1-INH replacement therapy. The C1-INH concentrate (500 U, C1-Inactivator HS; Behring, Marburg, FRG) was reconstituted with sterile distilled water to a final volume of $10 \mathrm{ml}$ and administered intravenously for a period of 5-10 min. The functional activity of $1 \mathrm{U}$ of C1-INH concentrate corresponded to the C1-INH activity in $1 \mathrm{ml}$ of normal human plasma. The C1-INH preparation was homogenous on SDS-PAGE and contained < 3\% of functionally inactive $M_{\mathrm{r}} 96,000$ C1-INH. Plasma samples were collected in heparinized tubes before infusion and at different time points (Table I) after administration and stored at $-80^{\circ} \mathrm{C}$.

Hemolytic assays. Determination of $\mathrm{CH} 50$ (26) and of complement components $\mathrm{C} 1, \mathrm{C} 2$, and $\mathrm{C} 4$ (27) was performed as previously described.

ELISA. The details of the experimental conditions (buffers, temperature, volumes, and incubation times) have been previously described $(15,25)$. The protein concentration of $\mathrm{Cl}-\mathrm{INH}$ and its functional activity were determined as described (25).

Binding of patients' autoantibodies to native C1-INH $\left(M_{\mathrm{r}} 105,000\right)$ and to patients' C1-INH $\left(M_{\mathrm{r}} 96,000\right)$ was determined on C1-INHcoated microtiter plates according to a previously described method (15). C1-INH bound to the ELISA plate was quantitated by incubation with serially diluted rabbit anti-C1-INH antibodies (Dakopatts, Copenhagen, Denmark), followed by a 1:1,000 dilution of peroxidaseconjugated goat anti-rabbit IgG antibodies (Bio-Rad Laboratories, Munich, FRG). For the detection of C1-INH-anti-C1-INH antibody complexes in plasma, microtiter plates were coated with a 1:200 dilution of polyclonal anti-C1-INH antibodies (Dakopatts) and incubated with plasma, and bound complexes were detected by a 1:200 dilution of peroxidase-labeled rabbit antibody to human IgG (Dako). The maximal amount of C1-INH-anti-C1-INH complexes attainable in patients' plasma was determined by preincubation of plasma with equal volumes of various concentrations of purified native $\mathrm{C} 1$-INH for $30 \mathrm{~min}$. The resulting immune complexes were detected with microtiter plates coated with polyclonal anti-C1-INH antibodies as described above. To determine the binding of patients' anti-C1-INH autoantibodies to C1-INH fixed to mouse monoclonal anti-C1-INH antibody $88 \mathrm{G} 2(28,29)$, microtiter plates were coated with $88 \mathrm{G} 2(10$ $\mu \mathrm{g} / \mathrm{ml})$ and incubated with $\mathrm{Cl}-\mathrm{INH}(20 \mu \mathrm{g} / \mathrm{ml})$. Serially diluted plasma was added and human IgG antibodies bound to $\mathrm{C} 1-\mathrm{INH}$ were detected as described above.

SDS-PAGE and autoradiography. SDS-PAGE was performed as previously described using 5-20\% (wt/vol) gradient gels (15). The gels were dried and exposed to x-ray films (Eastman Kodak Co., Rochester, NY) for 1-3 h.

Degradation of Cl-INH in patients' plasma in vitro. The degradation of ${ }^{125} \mathrm{I}-\mathrm{Cl}$-INH in patients' plasma was determined by SDS-PAGE after incubating $10 \mu \mathrm{l}$ of ${ }^{125} \mathrm{I}-\mathrm{Cl}$-INH $\left(4 \times 10^{5} \mathrm{cpm}\right)$ with $50 \mu \mathrm{l}$ of plasma for $3 \mathrm{~h}$ at $37^{\circ} \mathrm{C}(15) .10 \mu$ of the sample was then analyzed on SDS-PAGE.

Amino acid sequence analysis. Amino-terminal sequence analysis was performed by Edman degradation using $100 \mu \mathrm{g}$ of the patients' affinity-purified C1-INH and a gas phase sequencer (740A; Applied Biosystems, Foster City, CA) with an on-line 120A PTH analyzer (30).

\section{Results}

\section{Replacement therapy with C1-INH in patients with AAE type II}

Patient 1. Patient 1 (patient 2 from our previous study; 15) was treated with C1-INH concentrate on two different occasions. In our first study, patient 1 received $500 \mathrm{U}$ of $\mathrm{C} 1$-INH concentrate (Table I, day $1,13.30 \mathrm{~h}$ ) during an acute attack of angioedema with swelling of the lips, upon which he reacted with more severe edema. Administration of an additional 500 $\mathrm{U}$ of concentrate shortly after the first injection (day $1,14.00$ h) interrupted the progression of edema formation, which then resolved within $5 \mathrm{~h}$. Towards the end of this study the patient had a second attack and received another $500 \mathrm{U}$ of $\mathrm{Cl}$-INH concentrate (day $4,8.30 \mathrm{~h}$ ). In response to the first C1-INH injection, functional C1-INH activity increased up to $60 \%$ of normal within $5 \mathrm{~min}$, but dropped to $25 \%$ within the next 10 min. After the second infusion, C1-INH activity in plasma increased to $80-85 \%$ of normal and remained at this level for the next $2 \mathrm{~d}$. The amount of $\mathrm{Cl}$-INH-anti-C1-INH complexes increased 2- to 2.5 -fold within $15 \mathrm{~min}$ after the first infusion.

Table I. Complement and Anti-C1-INH Autoantibody Levels after Intravenous Administration of C1-INH Concentrate in a Patient with Acquired C1-INH Deficiency Type II

\begin{tabular}{|c|c|c|c|c|c|c|c|c|c|c|c|c|c|c|c|}
\hline & \multicolumn{5}{|c|}{ Day 1} & \multicolumn{3}{|c|}{ Day 2} & \multicolumn{2}{|c|}{ Day 3} & \multicolumn{4}{|c|}{ Day 4} & \multirow[b]{2}{*}{ NHP } \\
\hline & $\begin{array}{l}\downarrow \\
1: 30 \\
\text { p.m. }\end{array}$ & $\begin{array}{l}\text { 1:35 } \\
\text { p.m. }\end{array}$ & $\begin{array}{l}\text { 1:45 } \\
\text { p.m. }\end{array}$ & $\begin{array}{l}\downarrow \\
2: 00 \\
\text { p.m. }\end{array}$ & $\begin{array}{l}\text { 3:00 } \\
\text { p.m. }\end{array}$ & $\begin{array}{l}\text { 8:30 } \\
\text { a.m. }\end{array}$ & $\begin{array}{l}12: 00 \\
\text { p.m. }\end{array}$ & $\begin{array}{l}\text { 4:00 } \\
\text { p.m. }\end{array}$ & $\begin{array}{l}8: 30 \\
\text { a.m. }\end{array}$ & $\begin{array}{l}\text { 4:00 } \\
\text { p.m. }\end{array}$ & $\begin{array}{l}\downarrow \\
8: 30 \\
\text { a.m. }\end{array}$ & $\begin{array}{l}\text { 9:00 } \\
\text { a.m. }\end{array}$ & $\begin{array}{l}\text { 9:30 } \\
\text { a.m. }\end{array}$ & $\begin{array}{l}12: 30 \\
\text { p.m. }\end{array}$ & \\
\hline $\mathrm{CH} 50(\mathrm{U} / \mathrm{ml})$ & 0 & 0 & 0 & 2 & 5 & 20 & 23 & 22 & 25 & 23 & 22 & 23 & 22 & 22 & 25 \\
\hline $\mathrm{C} 1\left(\mathrm{U} / \mathrm{ml} \times 10^{3}\right)$ & 1 & 1 & 1 & 2 & 3 & 17 & 21 & 19 & 36 & 38 & 45 & 46 & 45 & 46 & 75 \\
\hline $\mathrm{C} 4\left(\mathrm{U} / \mathrm{ml} \times 10^{2}\right)$ & 1 & 2 & 5 & 7 & 20 & 18 & 15 & 11 & 3 & 1 & 1 & 1 & 1 & 3 & 80 \\
\hline C1-INH protein $(m g / d l)$ & 12 & 13 & 13 & 13 & 14 & 13 & 13 & 13 & 13 & 12 & 12 & 13 & 12 & 13 & 20 \\
\hline $\begin{array}{l}\text { C1-INH functional } \\
\text { activity (\% of normal) }\end{array}$ & 0 & 60 & 25 & 20 & 60 & 80 & 80 & 80 & 85 & 85 & 80 & 95 & 95 & 90 & 100 \\
\hline $\begin{array}{l}\text { Anti-C1-INH-antibody } \\
\text { titer }\left(\times 10^{2}\right)^{*} \\
\text { C1-INH-anti-C1-INH } \\
\text { complexes titer } \\
(\times 10)^{*}\end{array}$ & 5 & 6 & 5 & 6 & 7 & 6 & 7 & 6 & 6 & 7 & 7 & 7 & 7 & 7 & 0 \\
\hline & $\gamma$ & 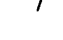 & 18 & 20 & 20 & 21 & 20 & 20 & 25 & 26 & 25 & 27 & 28 & 28 & 0 \\
\hline
\end{tabular}

$500 \mathrm{U}$ of $\mathrm{Cl}$-INH concentrate was injected at time points indicated by arrows. $\mathrm{CH} 50, \mathrm{C1}, \mathrm{C} 4, \mathrm{Cl}-\mathrm{INH}$ protein, functional activity, anti-C1INH antibodies, and C1-INH-anti-C1-INH complexes were determined in plasma samples collected at the indicated times. NHP, normal human plasma. * Dilution of plasma at which $50 \%$ of maximal binding occurs. 
Even though no further drastic increase of complexes was observed after the second injection, there was a slow but constant increase in C1-INH-anti-C1-INH complexes until the end of this study. C4 hemolytic activity started to increase after the first injection and reached $25 \%$ of normal levels after $1.5 \mathrm{~h}$. It remained stable for $\sim 18 \mathrm{~h}$ but then returned to preinfusion levels. In contrast to $\mathrm{C} 4, \mathrm{C} 1$ hemolytic activity increased very slowly and reached its maximal activity of $\sim 60 \%$ of normal at the end of this study. The immunochemically detectable levels of $\mathrm{C} 1-\mathrm{INH}$ protein and of anti-C1-INH autoantibodies remained unchanged during this study.

Since earlier in vitro studies showed that ${ }^{125} \mathrm{I}$-labeled $M_{\mathrm{r}}$ $105,000 \mathrm{C} 1-\mathrm{INH}$ is rapidly degraded to a $M_{\mathrm{r}} 96,000 \mathrm{C} 1-\mathrm{INH}$ in patients' plasma (15), we tested the collected plasma samples for their ability to cleave intact $\mathrm{C} 1-\mathrm{INH}$. The results presented in Fig. 1 show that degradation of ${ }^{125} \mathrm{I}-\mathrm{C} 1-\mathrm{INH}$ (track 1$)$ to $M_{\mathrm{r}}$ 96,000 C1-INH was completely abrogated after the first injection of C1-INH concentrate (track 2), but reappeared when C1-INH functional activity decreased (tracks 3 and 4; for comparison see also Table I). Infusion of another $500 \mathrm{U}$ of C1-INH concentrate completely abolished ${ }^{125} \mathrm{I}-\mathrm{C} 1-\mathrm{INH}$ cleavage for $\sim 40 \mathrm{~h}$ (tracks 5-9). Samples collected before (track 10) and during the onset of a new attack of angioedema (track 11) again showed a similar cleavage of ${ }^{125} \mathrm{I}-\mathrm{C} 1-\mathrm{INH}$ that disappeared after administration of another $500 \mathrm{U}$ of concentrate (tracks 12-14).

During another acute episode of angioedema (second study), the same patient received 1,000 U of C1-INH concentrate at a time. In contrast to the first study where $2 \times 500 \mathrm{U}$ of concentrate were injected with a delay of $30 \mathrm{~min}$, no exacerbation of the edema occurred and the patient's symptoms resolved within 10-15 h. C1-INH functional activity returned to $80 \%$ of normal serum levels within $30 \mathrm{~min}$ and C4 hemolytic activity peaked 6-7 $\mathrm{h}$ after the injection. As in the first study, the amount of $\mathrm{C} 1-\mathrm{INH}$-anti-C1-INH complexes increased about threefold after the injection, whereas the amount of $\mathrm{Cl}$ INH protein and of anti-C1-INH autoantibodies remained unchanged (data not shown).

Patient 2. The second patient (patient 1 in our previous study) had a four to five times higher anti-C1-INH antibody titer than patient 1 (15). In two different severe episodes of laryngeal edema this patient did not respond to infusion of 500 $\mathrm{ml}$ of fresh frozen plasma or 2,000 $\mathrm{U}$ of $\mathrm{C1}$-INH. Except for an increase (two- and sixfold) in C1-INH-anti-C1-INH antibody complexes immediately after the infusions, all other parameters tested above remained unchanged in samples collected at various time points after therapy with C1-INH (not shown). In addition, no significant changes in edema formation were observed in this patient during the replacement therapy with C1-INH.

\section{Amino acid sequence analysis of patients' C1-INH}

While the C1-INH in normal human serum had an $M_{\mathrm{r}}$ of 105,000 in SDS-PAGE, the patients' C1-INH had an $M_{\mathrm{r}}$ of only 96,000 (15). To determine the $M_{\mathrm{r}}$ differences between these two forms of C1-INH, C1-INH from patient plasma or C1-INH from normal human plasma was affinity purified and its $\mathrm{NH}_{2}$-terminal amino acid sequence was analyzed by automated Edman degradation. When normal C1-INH $\left(M_{\mathrm{r}}\right.$ $105,000)$ was subjected to amino-terminal sequence analysis, a unique amino acid sequence was identified, the sequence being identical to the amino terminus of the $\mathrm{Cl}$-INH molecule (data not shown). In contrast, when the patients' C1-INH $\left(M_{\mathrm{r}}\right.$ 96,000 ) was sequenced, in each cycle a double amino acid sequence was obtained, corresponding to the amino terminus of intact $\mathrm{C} 1-\mathrm{INH}$ and to the sequence starting at position 445 of the C1-INH sequence (Fig. 2). Quantitation of the phenylthiohydantoin-amino acids showed a 1:1 ratio of the $M_{\mathrm{r}}$ 96,000 fragment of C1-INH (residues 1-444) and of the 34 amino acid peptide (residues 445-478). This suggested that $\mathrm{C} 1-\mathrm{INH}$ is cleaved by one of its target proteases between the Arg-Thr bond (residues 444 and 445) in the active site of C1INH (Fig. 2).

Since the MAb (13E1) used for the affinity purification of $\mathrm{C} 1-\mathrm{INH}$ is directed against the 96,000-D fragment (residues $1-444)$, it is of interest that the small carboxyl-terminal fragment of C1-INH (residues 445-478) was copurified on this column. This indicated that this 34 amino acid peptide remains tightly bound to the $96,000-\mathrm{D}$ fragment after the cleavage of C1-INH by one of its target proteases. This is in accordance with previous findings showing that denaturing conditions ( $1 \%$ SDS) are required to separate this small peptide from C1-INH-C1s complexes (31).

\section{Analysis of patients' anti-C1-INH antibodies}

During the analysis of patients' anti-C1-INH antibodies we found that the patients' anti-C1-INH antibody titers (Fig. $3 A$ ) did not correlate with the amount of C1-INH-anti-C1-INH complexes detected in plasma (Fig. $3 \mathrm{~B}$ ). Although patient 2 had an antibody titer approximately four times higher than patient 1 , the latter had $\sim 8-10$ times more $\mathrm{C} 1$-INH-anti-C1INH complexes in plasma. Addition of purified $M_{\mathrm{r}} 105,000$ C1-INH to plasma increased the amount of complexes in vitro $\sim 4$ and 100 times in patients 1 and 2, respectively. This discrepancy was further analyzed by comparing the binding of anti-C1-INH antibodies to $M_{\mathrm{r}} 96,000 \mathrm{Cl}-\mathrm{INH}$ and to $M_{\mathrm{r}}$ 105,000 C1-INH. Fig. $3 C$ shows that patient 2 had a four times higher antibody titer than patient 1 when tested with $M_{\mathrm{r}}$ $105,000 \mathrm{C} 1-\mathrm{INH}$; whereas, when tested with $M_{\mathrm{r}} 96,000 \mathrm{C1}-$ INH, patient 1 had a two to three times higher antibody titer than patient 2. A polyclonal antibody to C1-INH bound to

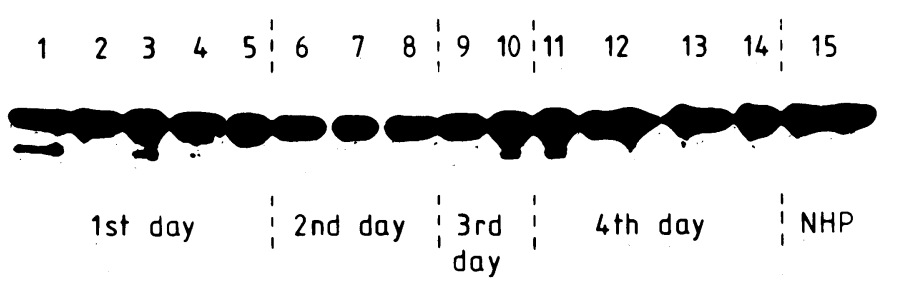

Figure 1. Cleavage of ${ }^{125} \mathrm{I}$-labeled $\mathrm{C} 1$-INH in plasma samples collected before and after the infusion of $\mathrm{Cl}$ INH concentrate in patient 1 with acquired angioedema type II. Plasma samples collected during the replacement therapy were incubated with ${ }^{125} \mathrm{I}$-labeled $\mathrm{Cl}$-INH for $3 \mathrm{~h}$ at $37^{\circ} \mathrm{C}$, separated in $5-20 \%$ SDS-PAGE, and exposed to $\mathrm{x}$-ray films. Samples were collected at the following time points: day 1, 1:30 p.m.(1), 1:35 p.m.(2), 1:45 p.m.(3), 2 p.m.(4), and 3 p.m.(5); day 2, 8:30 a.m.(6), 12 p.m.(7), and 4 p.m.(8); day 3, 8:30 a.m.(9) and 4 p.m.(10); and day 4, 8:30 a.m.(11), 9 a.m.(12), 9:30 a.m.(13), and 12:30 p.m.(14). Normal human plasma (NHP) served as a control(15). 


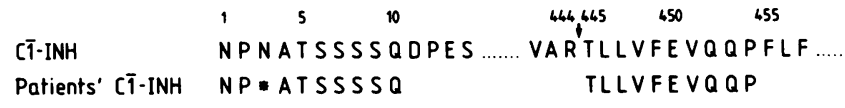

Figure 2. $\mathrm{NH}_{2}$-terminal amino acid sequence analysis of patients' $M_{\mathrm{r}}$ 96,000 C1-INH and its alignment with the C1-INH sequence (36). The cleavage site of $\mathrm{C} 1$-INH for its target proteases is marked by an arrow.

both C1-INH molecules equally well. In addition, one of the recently described anti-C1-INH MAbs $(28,29)$ inhibited the binding of the antibody of patient 1 to $\mathrm{Cl}-\mathrm{INH}$, but not of

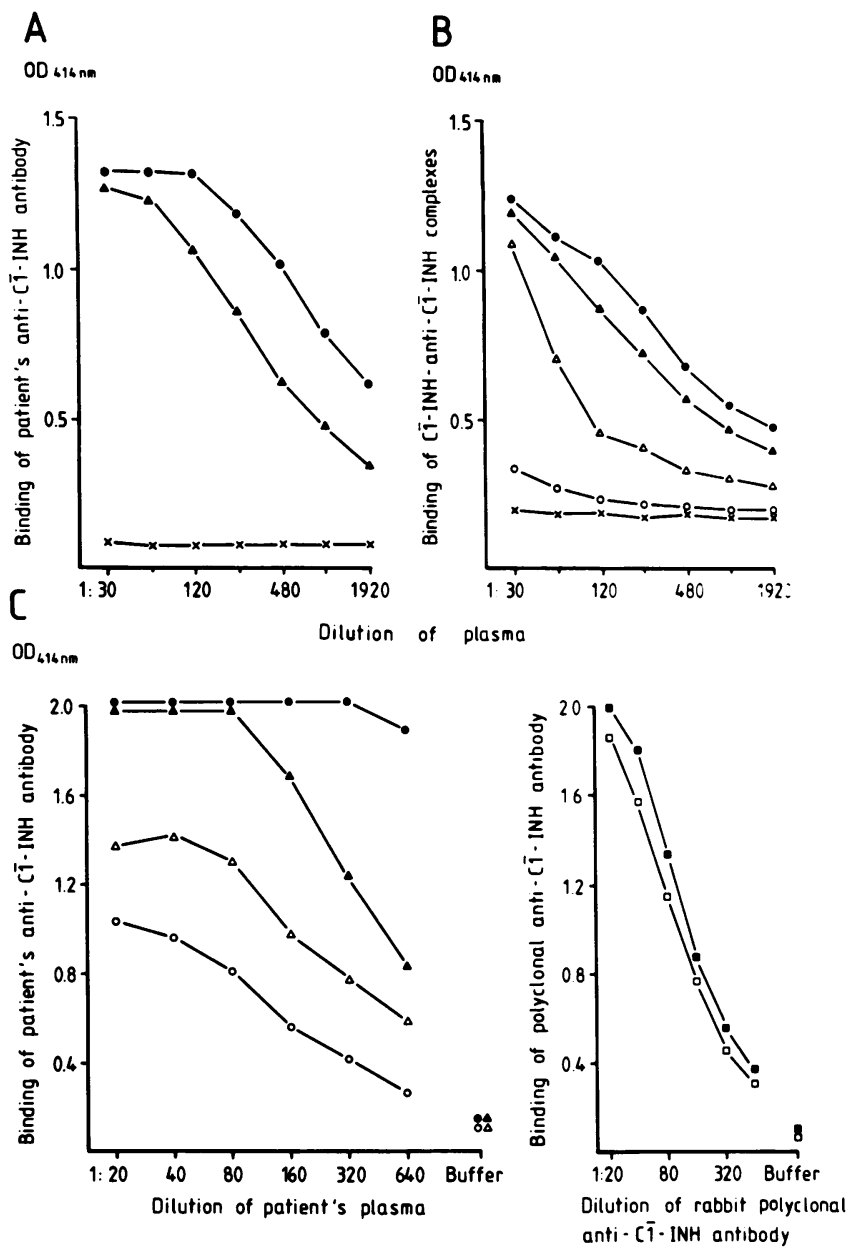

Figure 3. $(A)$ Determination of anti-C1-INH antibody titer in patients' plasma. Microtiter plates coated with $M_{\mathrm{r}} 105,000 \mathrm{Cl}-\mathrm{INH}$ were incubated with serially diluted plasma of patient $1(\Lambda)$ or patient $2(\bullet)$, and with normal human plasma $(x)$. IgG antibodies bound to C1-INH were detected by peroxidase-labeled antibody to human IgG. (B) Detection of C1-INH-anti-C1-INH immune complexes in patients' plasma. Serially diluted plasma of patient $1(\Delta, \Delta)$, patient 2 $(0, \bullet)$, or normal human plasma $(x)$ was pretreated with buffer $(\Delta, 0$, $\times$ ) or purified $M_{\mathrm{r}} 105,000 \mathrm{Cl}-\mathrm{INH}(\Lambda, \bullet, \times)$ and incubated with polyclonal anti-C1-INH antibody-coated microtiter plates. Cl-INHbound anti-C1-INH antibody was detected by peroxidase-labeled anti-human-IgG antibody. $(C)$ Binding of patients' anti-Cl-INH antibodies to purified $M_{\mathrm{r}} 105,000 \mathrm{Cl}$-INH and to patients' $M_{\mathrm{r}} 96,000$ C1-INH. $M_{\mathrm{r}} 105,000 \mathrm{Cl}-\mathrm{INH}(\Delta, \bullet, \square)$ or patients' $M_{\mathrm{r}} 96,000 \mathrm{Cl}-$ INH $(\Delta, O, \square)$ were bound to microtiter plates, incubated with serial dilutions of plasma of patient $1(\Delta, \Delta)$, patient $2(0, \bullet)$, and polyclonal anti-C1-INH antibody $(\square, \square)$. C1-INH-bound antibody was determined by peroxidase-labeled anti-human IgG and anti-rabbit IgG antibody, respectively.

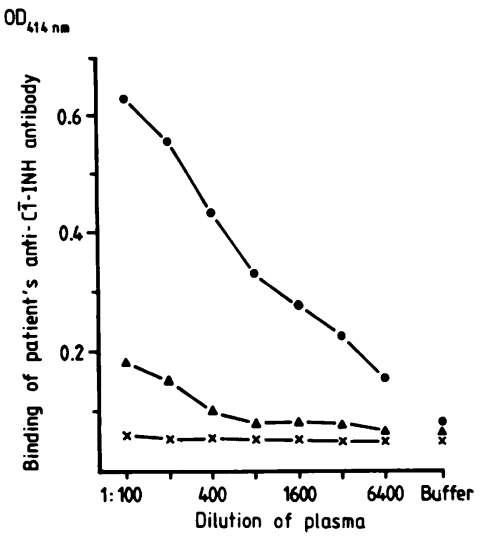

Figure 4. Binding of patients' autoantibodies to C1-INH bound to monoclonal anti-C1-INH antibody $88 \mathrm{G} 2$. C1-INH bound to MAb $88 \mathrm{G} 2$ was incubated with plasma of patient $1(\mathbf{\Delta})$ or patient 2 $(\bullet)$, or with normal human plasma (x). C1-INH-bound patients' anti-C1-INH antibodies were detected by peroxidase-labeled antihuman IgG antibodies.

patient 2 (Fig. 4). These results show that the patients' anti$\mathrm{Cl}$-INH antibodies recognize different epitopes in Cl-INH, indicating that patients with AAE type II produce distinct autoantibodies recognizing different epitopes in C1-INH.

\section{Discussion}

Acute, life-threatening angioedema in patients with HAE or AAE type $I$ is successfully managed by infusion of C1-INH (21-23). However, patients suffering AAE type II have been found to be resistant to $\mathrm{C} 1$-INH replacement therapy (partially or completely) $(15,24)$. To understand more about this we studied several parameters during C1-INH therapy in two patients with AAE type II.

The administration of $500 \mathrm{U}$ of $\mathrm{C} 1$-INH concentrate to patient 1 was insufficient for arresting an attack of angioedema. Rather, this amount of C1-INH was found to aggravate the edema (first attack). This was surprising since in HAE or AAE type II patients the same dose of C1-INH is usually effective and well tolerated, and attacks of angioedema precipitated by the infusion of $\mathrm{Cl}$-INH have never been described $(11,21-23)$. However, the patient's symptoms resolved after the injection of an additional $500 \mathrm{U}$ of C1-INH concentrate. When 1,000 U of C1-INH was injected at once in another angioedema attack of patient 1 (second study) no increase in edema formation was observed. Although it is difficult at present to draw any definite conclusion on the underlying processes, the data obtained from the parameters studied provide evidence for the following mechanism. After the first injection the functional activity of $\mathrm{Cl}-\mathrm{INH}$ is rapidly neutralized by the patient's anti-Cl-INH autoantibody. This is indicated by the transient increase in C1-INH functional activity and the subsequent two- to threefold rise in C1-INH-anti-C1-INH complexes in the patient's plasma (Table I). After the second injection no further increase in C1-INH-anti-C1-INH antibody complexes was observed. This suggests that no more free antiC1-INH antibodies were present to neutralize C1-INH function. The deterioration in patient's edema after the first C1INH injection remains unexplained. It could result from the increased formation of immune complexes causing a rise in uncontrolled activation of the classical pathway of complement in the patient's plasma. Alternatively, it could have been an idiosyncratic response, since no increase in angioedema was observed in patient 2 . No aggravation of edema was observed when $1,000 \mathrm{U}$ of $\mathrm{C} 1$-INH were administered to patient 1 (second study). In this case Cl-INH activity increased to $80 \%$ of 
normal, although the amount of C1-INH-anti-C1-INH complexes again rose threefold after the injection. Therefore, it is very likely that patients with AAE type II require more C1INH to abrogate an attack of angioedema than those with other types of angioedema since the autoantibodies have to be neutralized before a sufficient plasma level of functionally active C1-INH can be achieved.

In vitro, the amount of C1-INH required to neutralize the anti-C1-INH antibodies may be calculated by adding purified C1-INH to plasma and assessing the amount of C1-INH-antiC1-INH complexes. By using an ELISA, the addition of 40 (patient 1) or $400 \mu \mathrm{g}$ (patient 2) of purified C1-INH to $1 \mathrm{ml}$ of plasma resulted in a maximum immune complex formation (data not shown), indicating a complete neutralization of anti-C1-INH antibodies. These amounts of C1-INH correspond to the infusion of $600 \mathrm{U} \mathrm{(1} \mathrm{U}$ is equivalent to $1 \mathrm{ml}$ of plasma or $0.2 \mathrm{mg}$ of $\mathrm{C} 1-\mathrm{INH}$ ) and of $6,000 \mathrm{U}$ of $\mathrm{Cl}-\mathrm{INH}$ concentrate into patient 1 and patient 2 , respectively (an assumed average total plasma volume of 3 liters). Therefore, the calculated C1-INH dosages correspond to the evaluated effective dosage in the case of patient 1 and explain the inefficacy of 2,000 U of C1-INH in patient 2.

Throughout our study we did not see any significant changes in the amount of the patients' anti-C1-INH antibodies. However, the slight increase in C1-INH-anti-C1-INH complexes between the days 2 and 4 remains to be explained. After reaching a sufficient plasma level of C1-INH functional activity the response of patient 1 was found to be similar to the one reported for HAE and AAE type I patients (11, 20-23). C4 hemolytic activity transiently increased to $25 \%$ of normal levels and $\mathrm{C} 1$ titers reached $60 \%$ of normal at the end of the study. As previously suggested, this delay in increment in $\mathrm{Cl}$ and $\mathrm{C} 4$ titers might be due to the synthesis of new protein and/or the decreased catabolism of these proteins $(13,27)$. Interestingly, the $\mathrm{C} 4$ hemolytic activity decreased again after $\sim 18 \mathrm{~h}$, although C1-INH functional activity was still $80-85 \%$ of normal (Table I). Since even small soluble immune complexes have been found to activate $\mathrm{Cl}$ in the presence of diminished levels of C1-INH (32), the drop in C4 titer may be due to the consumption of $\mathrm{C} 4$ by activated $\mathrm{Cl}$ in the presence of patient's C1-INH-anti-C1-INH complexes.

Amino-terminal amino acid sequence analysis showed that $\mathrm{Cl}$-INH in these patients is cleaved between the Arg-Thr bond (residues 444-445) in its active site, presumably by one of its target proteases. In contrast to normal human serum, where such a cleavage results in the formation of irreversible, covalent C1-INH-enzyme complexes (33), no stable complexes were formed in the patients' plasma. Here these complexes seem to dissociate again into the active serine esterase and the modified, inactive C1-INH $\left(M_{\mathrm{r}} 96,000\right)$. This dissociation was postulated to be due to the presence of the autoantibodies to C1-INH $(34,35)$. Therefore, these antibodies may modify C1INH-target protease interactions as follows:

normal individuals, $\mathrm{E}+\mathrm{I} \rightleftharpoons \mathrm{E}:: \mathrm{I} \rightarrow \mathrm{E}-\mathrm{I}^{*}$;

AAE type II patients, $\mathrm{E}+\mathrm{I} \rightleftharpoons \mathrm{E}:: \mathrm{I} \rightarrow \mathrm{E}-\mathrm{I}^{*} \rightarrow \mathrm{E}+\mathrm{I}^{*}$,

where $\mathrm{E}=$ enzyme, $\mathrm{I}=\mathrm{C} 1-\mathrm{INH}$, and $\mathrm{I}^{*}=$ modified, inactive $\mathrm{Cl}-\mathrm{INH}$. According to this scheme, the enzyme is released in an active form and can bind to and inactivate another C1-INH molecule. Therefore, small amounts of active enzyme may consume large amounts of $\mathrm{Cl}-\mathrm{INH}$, thus decreasing the halflife of functionally active C1-INH in AAE type II patients.

We have also shown in this study that the patients' antiC1-INH antibodies recognize different epitopes in the C1-INH molecule (Figs. 3 and 4). This indicates that patients with AAE type II are heterogenous with respect to their anti-C1-INH antibodies. The antibody of patient 2 was found to recognize the 105,000-D C1-INH more than 100 times better than the 96,000-D C1-INH when compared with only a fourfold difference in patient 1 (Fig. $3 \mathrm{C}$ ). Therefore, the discrepancy between the titer of the antibody and the amount of C1-INHanti-C1-INH complexes in the patients' plasma is due to a difference in the recognition of the $96,000-\mathrm{D}$ C1-INH by the patients' antibodies (Fig. $3 A$ and $B$ ).

In regard to $\mathrm{Cl}-\mathrm{INH}$ replacement therapy, the difference in the recognition of $M_{\mathrm{r}} 105,000 \mathrm{C1}-\mathrm{INH}$ and $M_{\mathrm{r}} 96,000 \mathrm{C1}-\mathrm{INH}$ may also be of therapeutic relevance. The low affinity of the antibody for the $M_{\mathrm{r}} 96,000 \mathrm{Cl}-\mathrm{INH}$ may indicate that C1-INH injected into patient 2 will not only bind to free autoantibodies, but will also dissociate the existing $M_{\mathrm{r}} 96,000 \mathrm{C} 1-\mathrm{INH}-$ anti-C1-INH complexes to form the more stable $M_{\mathrm{r}} 105,000$ C1-INH-anti-C1-INH antibody complexes. In contrast, the anti-C1-INH antibody of patient 1 will form more stable complexes with the $M_{\mathrm{r}} 96,000 \mathrm{C} 1-\mathrm{INH}$ and the injected native C1-INH would not dissociate the existing complexes. As a consequence, patient 2 would require more C1-INH concentrate to neutralize the autoantibodies than patient 1 . Therefore, these differences in the affinity of the anti-C1-INH autoantibodies for the $M_{\mathrm{r}} 105,000 \mathrm{C} 1-\mathrm{INH}$ and the $M_{\mathrm{r}} 96,000$ C1-INH could be useful to predict whether or not C1-INH replacement therapy will be successful in a given patient suffering from AAE type II.

In summary, the responses of two patients suffering from AAE type II to replacement therapy with C1-INH were assessed. In comparison to HAE or AAE type I, patients with AAE type II were found to require higher dosages of C1-INH to overcome the neutralizing effect of the anti-C1-INH antibodies present in the plasma and to achieve sufficient plasma levels of functionally active C1-INH. In one patient the efficacy of the treatment was also evidenced by the in vivo synthesis of $\mathrm{C} 4$ and $\mathrm{Cl}$. However, the therapeutic effect in this patient was only transient, presumably because of the activation of $\mathrm{Cl}$ in the presence the C1-INH-anti-C1-INH complexes and the subsequent consumption of $\mathrm{C} 4$ and $\mathrm{Cl}-\mathrm{INH}$. The failure in C1-INH treatment in the second patient most probably was due to the higher anti-Cl-INH antibody titer and the lower affinity of the patient's anti-C1-INH autoantibody for the abnormal $M_{\mathrm{r}} 96,000 \mathrm{C} 1-\mathrm{INH}$.

\section{Acknowledgments}

We thank D. Becherer, D. Grossberger, and R. Palacios for critical reading of our manuscript, and M. Zöller-Schütz, G. Lehne, and D. Avila for their excellent technical assistance.

The Basel Institute for Immunology was founded and is entirely supported by F. Hoffman-La Roche Ltd., Co., Basel, Switzerland. J. Alsenz is a recipient of a European Molecular Biology Organization fellowship, ALTF 298-1987.

\section{References}

1. Ziccardi, R. J. 1982. A new role for C1-inhibitor in homeostasis: control of the first component of human complement. J. Immunol. 128:2505-2508. 
2. Donaldson, V. H., and R. R. Evans. 1963. A biochemical abnormality in hereditary angioneurotic edema: absence of serum inhibitor of Cl'-esterase. Am. J. Med. 35:37-44.

3. Späth, P. J., B. Wüthrich, and R. Bütler. 1984. Quantification of $\mathrm{Cl}$-inhibitor functional activities by immunodiffusion assay in plasma of patients with hereditary angioedema: evidence of a functional critical level of C1-inhibitor concentration. Complement. 1:147-159.

4. Rosen, F. S., P. Charache, J. Pensky, and V. H. Donaldson. 1965. Hereditary angioneurotic edema: two genetic variants. Science (Wash. DC). 148:957-958.

5. Cicardi, M., T. Igarashi, F. S. Rosen, and A. E. Davis III. 1987. Molecular basis for the deficiency of complement 1 inhibitor in type 1 hereditary angioneurotic edema. J. Clin. Invest. 79:698-702.

6. Cicardi, M., L. Bergamaschini, B. Marasini, G. Boccassini, A. Tucci, and A. Agostoni. 1982. Hereditary angioedema: an appraisal of 104 cases. Am. J. Med. Sci. 284:2-9.

7. Rosen, F. S., C. A. Alper, J. Pensky, M. R. Klemperer, and V. H. Donaldson. 1971. Genetically determined heterogeneity of the $\mathrm{Cl}$ esterase inhibitor in patients with hereditary angioneurotic edema. $J$. Clin. Invest. 50:2143-2149.

8. Donaldson, V. H., C. J. Wagner, B. Tsuei, G. Kindness, D. H. Bing, R. A. Harrison, and F. S. Rosen. 1987. Interactions of plasma kallikrein and $\mathrm{C} 1 \mathrm{~s}$ with normal and dysfunctional $\mathrm{Cl}$-inhibitor proteins from patients with hereditary angioneurotic edema: analytic gel studies. Blood. 69:1096-1101.

9. Donaldson, V. H., R. A. Harrison, F. S. Rosen, D. H. Bing, G. Kindness, C. J. Wagner, and S. Awad. 1985. Variability in purified dysfunctional $\mathrm{Cl}$-inhibitor proteins from patients with hereditary angioneurotic edema. Functional and analytical gel studies. J. Clin. Invest. $75: 124-132$.

10. Gelfand, J. A., G. R. Boss, C. L. Conley, R. Reinhart, and M. M. Frank. 1979. Acquired $\mathrm{Cl}$ esterase inhibitor deficiency and angioedema: a review. Medicine (Baltimore). 58:321-328.

11. Cicardi, M., D. Frangi, L. Bergamanschini, M. Gardinali, G. Sacchi, and A. Agostoni. 1985. Acquired Cl inhibitor deficiency with angioedema symptoms in a patient with Echinococcus granulosus. Complement. 2:133-139.

12. Geha, R. S., I. Quinti, K. F. Austen, M. Cicardi, and F. S. Rosen. 1985. Acquired $C 1$ esterase inhibitor deficiency associated with antiidiotypic antibody to monoclonal immunoglobulins. $N$. Engl. J. Med. 312:534-540.

13. Sheffer, A. L., K. F. Austen, F. S. Rosen, and D. T. Fearon. 1985. Acquired deficiency of the inhibitor of the first component of complement: report of five additional cases with commentary on the syndrome. J. Allergy Clin. Immunol. 75:640-646.

14. Frank, M. M., J. A. Gelfand, and J. P. Atkinson. 1976. Hereditary angioedema: the clinical syndrome and its management. Ann. Intern. Med. 84:580-593.

15. Alsenz, J., K. Bork, and M. Loos. 1987. Autoantibody-mediated acquired deficiency of $\mathrm{Cl}$ inhibitor. N. Engl. J. Med. 316:1360-1366.

16. Jackson, J., R. B. Sim, A. Whelan, and C. Feighery. 1986. An IgG autoantibody which inactivates $\mathrm{Cl}$-inhibitor. Nature (Lond.). 323:722-724.

17. Frank, M. M., A. Malbran, H. Simms, K. Melez, M. Santaella, C. Hammer, and L. Fries. 1987. Acquired angioedema type II (AAEII): a new autoimmune disease. Clin. Res. 35:641a. (Abstr.)

18. Malbran, A., C. Hammer, M. M. Frank, and L. Fries. 1987. Acquired angioedema type II (AAE-II): mechanism of action of an autoantibody directed against $\mathrm{Cl}$ esterase inhibitor (C1EI). Clin. Res. 35:255a. (Abstr.)
19. Gadek, J. E., S. W. Hosea, J. A. Gelfand, and M. M. Frank. 1979. Response of variant hereditary angioedema phenotypes to danazol therapy. J. Clin. Invest. 64:280-286.

20. Cohen, S. H., S. Koethe, F. Kozin, G. Rodey, J. Arkins, and J. N. Fink. 1978. Acquired angioedema associated with rectal carcinoma and its response to danazol therapy. J. Allergy Clin. Immunol. 62:217-221.

21. Bergamanschini, L., M. Cicardi, A. Tucci, M. Gardinali, D. Frangi, C. Valle, and A. Agostoni. 1983. C1-INH concentrate in the therapy of hereditary angioedema. Allergy (Copenh.). 38:81-84.

22. Kleinhans, D., A. Schach, U. Rüther, and P. Jipp. 1986. Immunocytoma with acquired C1-esterase-inhibitor deficiency and recurrent oedema. Dtsch. Med. Wochenschr. 111:742-744.

23. Gadek, J. E., S. W. Hosea, J. A. Gelfand, M. Santanella, M. Wickerhauser, D. C. Triantaphyllopoulos, and M. M. Frank. 1980. Replacement therapy in hereditary angioedema: successful treatment of acute episodes of angioedema with partially purified $\mathrm{C} 1$ inhibitor. $N$. Engl. J. Med. 302:542-546.

24. Frank, M. M. 1986. C1 esterase inhibitor: clinical clues to the pathophysiology of angioedema. J. Allergy Clin. Immunol. 78:848850.

25. Alsenz, J., and M. Loos. 1987. Simplified methods for the purification, quantitation, and functional estimation of human complement $\mathrm{Cl}$-inhibitor (C1-INH) with a monoclonal anti-C1-INH antibody. J. Immunol. Methods. 96:107-114.

26. Heinz, H. P., T. Hitschold, M. Latsch, and M. Loos. 1983. Vereinfachter Mikroassay zur Bestimmung der gesamthämolytischen Komplementaktivität, CH50. Lab. Med. 9:320-323.

27. Rapp, H. J., and T. Borsos. 1970. Molecular Basis of Complement Action. Appleton-Century-Crofts, New York. 164 pp.

28. Alsenz, J., and M. Loos. 1987. Monoclonal antibodies to C1inhibitor (C1-INH): characterization of structural and functional domains. Complement. 4:126a. (Abstr.)

29. Alsenz, J., and M. Loos. 1988. A rapid and simple ELISA for the determination of duplicate monoclonal antibodies during epitope analysis of antigens and its application to the study of C1-INH. $J$. Immunol. Methods. 109:75-84.

30. Hedwig, R. M., M. W. Hunkapiller, L. E. Hood, and W. J. Dreyer. 1981. A gas-liquid solid phase peptide and protein sequenator. J. Biol. Chem. 256:7990-7997.

31. Salvesen, G. S., J. J. Catanese, L. F. Kress, and J. Travis. 1985 Primary structure of the reactive site of human C1-inhibitor. J. Biol. Chem. 260:2432-2436.

32. Doekes, G., L. A. van Es, and M. R. Daha. 1983. C1-inactivator: its efficiency as a regulator of classical complement pathway activation by soluble IgG aggregates. Immunology. 49:215-222.

33. de Schapira, M., A. Agostini, J. A. Schifferli, and R. W. Colman. 1985. Biochemistry and pathophysiology of human $\mathrm{C} 1$ inhibitor: current issues. Complement. 2:111-126.

34. Jackson, J., R. B. Sim, K. Whaley, I. Jones, and C. Feighery. 1987. Autoantibody-mediated cleavage of normal $\mathrm{Cl}$ inhibitor by purified $\mathrm{Clr}$, C1s and plasmin. Complement. 4:173a. (Abstr.)

35. Malbran, A., C. H. Hammer, M. M. Frank, and L. F. Fries. 1988. Acquired angioedema: observations on the mechanism of action of autoantibodies directed against $\mathrm{Cl}$ esterase inhibitor. J. Allergy Clin. Immunol. 81:1199-1204.

36. Bock, S. C., K. Shriver, E. Nielsen, H. T. Thogersen, B. Wiman V. H. Donaldson, R. L. Eddy, J. Marrinan, E. Radzijewska, R. Huber, T. B. Shows, and S. Magnusson. 1986. Human Cl inhibitor: primary structure, cDNA cloning, and chromosomal localization. Biochemistry. 25:4292-4301. 